\title{
A CONTRIBUIÇÃO DE PEIRCE PARA A TEORIA DA COMUNICAÇÃO
}

\section{PEIRCE'S CONTRIBUTION FOR COMMUNICATION THEORY}

VINICIUS ROMANINI*

RESUMO: Charles Sanders Peirce (1839-1914) deu importantes contribuições para a filosofia, para a matemática e para a lógica. Mas foi principalmente para esta última que a maior parte de seus estudos se voltou. Sua teoria geral dos signos, ou semiótica, foi desenvolvida como uma tentativa de descobrir a lógica que fundamenta as nossas concepções do real e como o conhecimento cresce a partir do compartilhamento e debate de opiniões no interior de uma comunidade. Por isso, o pragmatismo - seu maior legado para a filosofia - foi por ele definido como um método para clarear nossas ideias a partir da análise dos possíveis efeitos que a adoção de um conceito (uma crença) poderia produzir. A partir de 1905, Peirce passou a considerar o signo como o meio para a transmissão das formas que fundamentam os conceitos, e a comunicação como a mais elevada dos vários tipos de ação do signo. Na semiose, os símbolos se mantêm falíveis e em contínua transformação porque essa é sua natureza: crescer e se desenvolver num uni-

* Docente da USP - Universidade de São Paulo. E-mail: vinicius.romanini@usp.br . 
verso inteligível e repleto de sentido. Nesse realismo semiótico baseado numa teoria social do conhecimento, a estética fundamenta a ética, e estas fornecem a base para a lógica compreendida agora como uma teoria geral da comunicação.

PALAVRAS-CHAVE: Comunicação. Peirce. Semiose. Informação. Lógica.

ABSTRACT: Charles Sanders Peirce (1839-1914) made important contributions to Philosophy, Mathematics and Logic. But it was mainly to the latter that most of his studies turned. His general theory of signs, or semiotics, was developed as an attempt to discover the logic that underlies our conceptions of the real and how knowledge grows from confronting and sharing opinions within a community. So, pragmatism - his greatest legacy to Philosophy - was defined by him as a method to clean up our ideas from the analysis of the possible effects that the adoption of a concept (a belief) could produce. From 1905 on, Peirce came to regard the sign as the medium for the transmission of forms that ground the concepts, and communication as the most important of the various types of sign actions. In semiosis, the symbols remain fallible and constantly changing because that is their nature: to grow and develop in a universe that is intelligible and filled with meaning. In this semiotic realism, based on a social theory of knowledge, aesthetics bases ethics, and these both provide the basis for the logic - now understood as a general theory of communication.

KEYWORDS: Communication. Peirce. Semiosis. Information. Logic. 
Charles Sanders Peirce nunca escreveu um tratado de semiótica. As ideias de sua teoria dos signos precisaram ser coletadas de algumas dezenas de artigos publicados, mas principalmente de manuscritos e anotações em cadernos e de cartas que trocou ao longo de quase meio século. A compilação dos textos coletados de tempos e fontes tão diversas mostra uma teoria em constante evolução. Não houve um só momento em que, ao se debruçar sobre sua classificação dos signos, não introduzisse novos termos e revisasse sua produção anterior. Ainda assim, na sua vasta arquitetura filosófica, a semiótica é um liame tênue capaz de colocar em contato as várias outras teorias e doutrinas que desenvolveu. Ela comparece em artigos e cartas dedicados à lógica, à matemática e à metafísica, obrigando-o a adaptar a terminologia semiótica ao vocabulário de cada uma dessas ciências. Por isso, a tarefa de mapear a evolução da semiótica de Peirce na direção de uma teoria semiótica da comunicação exige de seus estudiosos o conhecimento nas várias disciplinas com as quais dialogou algo que só foi possível recentemente e, ainda assim, de maneira incompleta (ROMANINI, 2005).

Uma questão de saída, que ainda produz debates entre os scholars, é sobre como devemos encarar o desenho geral da evolução do pensamento de Peirce. Alguns, como Ransdell (1986), creem que ele manteve, durante toda sua carreira, a essência dos argumentos apresentados no artigo seminal de sua filosofia "Sobre uma nova lista de categorias", publicado em 1968 (e aqui referido na forma abreviada de "Nova Lista"). Murphey (1993, p. 3), por outro lado, defende que a arquitetura filosófica de Peirce, incluindo sua semiótica, assemelha-se a uma casa cujo interior está em contínua reforma, embora preservando o máximo de sua estrutura básica. Short (2004) argumenta que Peirce abandonou muitas de suas ideias ju- 
venis, principalmente aquelas ligadas ao seu passado nominalista. Savan (1977, p. 179) chega a afirmar que teoria dos signos do Peirce maduro tem pouco a ver com sua primeira formulação na década de 1860. É preciso, portanto, conhecer um pouco sobre como essas mudanças podem ter acontecido para entendermos como a comunicação ganhou crescente interesse e relevância em sua produção intelectual.

\section{Síntese de tradições}

Uma das grandes batalhas intelectuais de Peirce foi produzir uma síntese filosófica que pudesse extrair o melhor das tradições idealista (germânica) e empirista (britânica), mas sem perder de vista os últimos desdobramentos científicos de sua época. Essa preocupação o levou a um mergulho na filosofia medieval, numa tentativa de encontrar ali as raízes das duas tradições que ele procurara unificar. A partir da leitura de escolásticos como Guilherme de Ockham e Duns Scotus, Peirce retrocedeu até a teoria dos signos dos estóicos e, principalmente, à definição de implicação material creditada a Filo de Megara (ZEEMAN, 1986), considerada por Peirce como a mais essencial das relações lógicas. De outro lado, levou-o a leitura dos grandes nomes da filosofia alemã, como o filósofo e matemático Leibniz, Kant e os idealistas Hegel e Schelling.

0 lado naturalista de Peirce, vinculado à sua prática como químico e geodésico (ele foi responsável por desenhar e realizar experimentos para medir a curvatura da Terra a partir de pêndulos de enorme precisão, por exemplo), também teve forte influência no desenvolvimento de sua semiótica. Além disso, Peirce estava atento aos desdobramentos do evolucionismo das espécies, lançado por Darwin em 1959, 
e das muitas vantagens de se realizar uma classificação dos elementos químicos de Mendeleev segundo suas valências e possibilidades de ligação. Ele também estudou a classificação zoológica realizada por Louis Agassiz, um biólogo adepto de Lamarck e de quem Peirce foi aluno direto.

Inspirado por esses diagramas classificatórios, Peirce conclui que toda ciência deveria começar com um esforço para desvendar e elencar as classes naturais dadas na percepção - ou seja, pela fenomenologia, que ele prefere chamar de faneroscopia (do grego phaneron: aparência, manifestação). Feita a tipologia inicial, deveria então proceder ao arranjo das classes naturais de acordo com suas relações e afinidades. Esse método, se estendido a todas as formas de conhecimento, deveria produzir uma classificação arquitetônica de todas as ciências (não só as atuais, mas também as futuras, que se encaixariam nas lacunas deixadas abertas), em que as mais abstratas, como a matemática, deveriam oferecer subsídios para as mais empíricas.

A primazia da matemática no edifício classificatório das ciências, bem como seu papel de provedora de subsídios para as demais ciências, fizeram com que Peirce mantivesse uma incessante pesquisa sobre os fundamentos da matemática e sua relação com outras ciências, principalmente com a lógica. Vem da matemática, por exemplo, a terminologia de suas três categorias fundamentais: primeiridade, segundidade e terceiridade. Do estudo da relação entre lógica e matemática nasceu uma lógica algébrica, que Peirce desenvolveu independentemente de Frege. Peirce também produziu uma axiomatização dos números naturais e estudou detalhadamente os postulados e teoremas da geometria euclidiana, bem como as consequências das novas geometrias propostas por Riemann e Lobatchevski. Esses estudos o levaram a pesquisar a noção de 
relação, de infinito e de contínuo, que ele procurou aplicar a um tipo especial de topologia estreitamente relacionada à sua semiótica e à sua lógica gráfica.

No sistema classificatório das ciências proposto por Peirce, a filosofia é considerada a que busca normatizar o que a faneroscopia descobre, não só dando sentido geral, mas também analisando e comunicando os significados de forma que as descobertas tenham efeitos práticos concebíveis entre os intérpretes que compartilham esse conhecimento. Deve ser dividida triadicamente em estética (a mais fundamental das ciências normativas, que oferece subsídios às demais), ética (a ciência normativa que estuda a ação propositada) e lógica (a ciência normativa que estuda a relação entre os signos, seus objetos e seus efeitos).

Na verdade, nas suas primeiras tentativas de classificar as ciências, a lógica aparecia como um ramo da semiótica: enquanto esta última se preocupava com signos em geral, caberia à primeira focar sua atenção nos símbolos e nas figuras lógicas diretamente relacionadas a eles: o termo, a proposição e o argumento (este último também chamado de silogismo ou inferência). De fato, a primeira contribuição importante de Peirce para a lógica, ainda na década de 1860, foi uma classificação dos silogismos aristotélicos sob a égide de suas categorias. Mais tarde, passou a considerar semiótica e lógica como sinônimas (HOUSER, 1992, p. XXX) e boa parte de sua pesquisa concentrou-se na produção de uma classificação para todos os signos possíveis.

A esse trabalho de desvendar tipologias de signos e classificá-las Peirce deu o nome de gramática especulativa, que deveria ser o primeiro ramo da semiótica. 0 segundo grande ramo da semiótica é a lógica crítica, considerada como a ciência da verdade das representações, ou seja, o estudo da 
possibilidade de um signo representar seu objeto verdadeiramente. Por fim, Peirce concebeu a retórica universal (ou metodêutica) como o terceiro ramo da semiótica, definindo-a como o estudo dos efeitos do signo sobre seus intérpretes ou, dito de outra maneira, o estudo de como a forma é transmitida do objeto ao interpretante, tendo o signo como veículo. É sob o ponto de vista da retórica que a semiose é vista como comunicação orientada para um propósito ou causa final.

Sua teoria semiótica da comunicação é, portanto, o resultado de um percurso intelectual de quarenta anos de pesquisa científica e filosófica, tendo destilado conceitos vindos de todas as ciências e épocas que estavam acessíveis às suas pesquisas. Uma teoria semiótica da comunicação peirceana precisa compreender e incorporar as razões filosóficas que fizeram Peirce caminhar no sentido de uma lógica da produção e compartilhamento de informação.

\section{A centralidade da semiótica no pensamento de Peirce}

O estudo dos signos está presente na vida intelectual de Peirce desde pelo menos meados da década de 1860, quando ele era ainda um aluno de graduação em Harvard. Em 1865, com apenas 26 anos, Peirce fez uma série de conferências sobre a lógica da ciência, em que ele demonstra dominar a filosofia transcendental de Kant, os fundamentos da lógica e da teoria da probabilidade, bem como a questão sobre a representação em geral - ou como surgem os conceitos na mente humana.

Peirce derivou sua concepção de semiótica como lógica provavelmente da leitura dos filósofos empiristas ingleses. 
John Locke, em 1690, já afirmara a necessidade de um novo tipo de lógica, que batizou de sēmeiōtikê, explicando que se trataria de uma doutrina dos signos de que a mente faz uso para o entendimento das coisas. Com efeito, a questão sobre a origem das nossas primeiras concepções é um problema lógico de primeira magnitude, pois dele depende a garantia de verdade das proposições. A conclusão de Peirce é de que questões ontológicas quanto à realidade do mundo, ou epistemológicas quanto à verdade das nossas concepções não podem ser resolvidas na busca de princípios ou leis absolutas, mas, sim, no processo contínuo de significação que ocorre quando "fazemos perguntas à natureza", num diálogo entre nós e a realidade, que chamamos de "experiência". A disputa entre nominalismo e realismo, que comparece a várias fases do pensamento de Peirce, se refere justamente a estas duas atitudes epistemológicas.

Para lançar luz sobre esse problema, Peirce enfrenta o "cadeado que Kant colocou na porta da filosofia" (CP, 5.3481 $)$, ou seja, a questão sobre como são possíveis juízos sintéticos a priori. É a partir desta questão que brota toda a teoria dos signos de Peirce, e principalmente o conceito de semiose, ou ação do signo. Em Kant, as condições de possibilidade da experiência se fundamentam na estética, considerada, na filosofia transcendental, como o estudo da síntese do múltiplo das impressões sensíveis na unidade da proposição. Para o pai do transcendentalismo, as categorias a priori do espaço e do tempo são responsáveis por organizar a massa de impressões oferecidas pela sensibilidade num conceito inteligível. Ou seja, as impressões de sentido não são ininteligíveis em si mesmas, puro noumeno, mas ganham inteligibilidade graças

1 CP: Collected Papers (PEIRCE, 1931-1958). 0 primeiro número indica o volume, os demais, após o ponto, indicam o parágrafo. 
ao trabalho da mente humana, que as guindam para a dimensão do fenômeno e da análise crítica.

Apesar da admiração que sempre sentiu por Kant e sua obra intelectual, Peirce acaba por recusar a solução kantiana dos julgamentos sintéticos a priori a partir do artigo "Uma conjectura ao Enigma” (EP, 1.245-179²). 0 motivo, segundo Peirce, é de que a proposta de Kant conduziria a filosofia ao beco sem saída do nominalismo, pois deposita a inteligibilidade do fenômeno somente no trabalho da mente humana - negando, portanto, que a realidade possua as condições de sua própria inteligibilidade. Se quisermos avançar uma alternativa a toda epistemologia nominalista, inclusive a do transcendentalismo kantiano, então precisamos oferecer outra solução para a síntese de conceitos a partir da experiência.

A proposta que Peirce oferece é surpreendente: não existe a síntese a priori porque estamos imersos no fluxo da causação que organiza tanto os fenômenos naturais quanto os conceitos em nossas mentes. Ou seja, uma mesma lei da causação fundamenta tanto o desenvolvimento do simples para o complexo, que observamos na natureza, quanto o processo de aprendizado, que nos permite ampliar nosso conhecimento sobre a realidade. Em outras palavras, tanto a fertilidade dos processos naturais quanto a dos nossos pensamentos se baseiam no contínuo que confere transitividade aos processos de causação. A semiose tende a estados gerais futuros capazes de organizar e controlar ocorrências particulares. A teleologia da causação final aristotélica substitui a síntese a priori kantiana.

De fato, a síntese da causação é análoga ao esquematismo

2 EP: Essential Peirce (PEIRCE, 1992; 1998). O primeiro número indica o volume, os demais, após dois pontos, indicam as páginas. 
do tempo, visto agora não mais como categoria a priori, mas, sim, como fluxo contínuo que estrutura a realidade internamente, permitindo que o possível se atualize e que a atualidade se generalize enquanto se desenvolve na direção de um futuro vago e indeterminado. Esse processo ocorre nas regiões mais profundas de todo tipo de mente ativa. Estamos aqui no berço das nossas cognições, em que sentimentos e informação são indistinguíveis. Para Peirce, os sentimentos são o trilho subterrâneo e não consciente por onde desliza o trem dos nossos pensamentos. Caso se interrompa o fluxo do sentir, da causação sensível e estética, fundamento do fluir temporal, veremos que o pensar racional se apaga como uma lâmpada desconectada da energia que a alimenta. A causação é, portanto, a lei da mente, a da associação entre ideias (por similaridade ou por contiguidade), capaz de gerar informação a partir das sensações que brotam da percepção.

\section{O conceito de informação em Peirce}

O ponto de partida para a teoria semiótica da informação está na filosofia britânica. Peirce foi bastante influenciado pela lógica de Stuart Mill, bem como pelos escritos de William Hamilton. 0 empirismo inglês enfatizava a importância da inferência indutiva e os conceitos de conotação (as qualidades predicáveis de um termo) e denotação (as coisas às quais um termo se aplica) como quantidades lógicas fundamentais. Os lógicos ingleses consideravam essas duas quantidades essenciais para a classificação das formas de raciocínio, as quais também exerceram um papel importante na formulação da semiótica de Peirce.

No entanto, já nos seus primeiros textos, Peirce afirma 
que essas duas quantidades não dão conta de um fenômeno central na lógica, que é o crescimento ou evolução do significado dos termos. Por isso, ele expande a dicotomia denotação/ conotação introduzindo um terceiro elemento: a informação (chamada também de significação e predicação). A informação é um componente idealista lançado por Peirce no interior da lógica empirista, mas os desdobramentos dessa introdução teriam consequências futuras importantes para sua teoria dos signos, principalmente em sua fase madura. Enquanto a semiótica misturava-se indissoluvelmente com a metafísica, a informação passava a ser o fundamento de um tipo de "realismo idealista", ou "idealismo objetivo" (IBRI, 1992, p. 55), que prega serem as formas universais os agentes que determinam os objetos do mundo. 0 idealismo objetivo é um conceito fundamental para entender a teoria semiótica da comunicação, principalmente por se contrapor à maneira como a informação é atualmente compreendida nos círculos científicos.

É provável que Peirce tenha sido o primeiro pensador a adotar o conceito de informação num contexto científico. Para ele, a informação é um fenômeno análogo ao de desenvolvimento, de aumento na complexidade, de incorporação de variedade num sistema. É o processo pelo qual algumas poucas coisas, apresentando algumas propriedades simples, evoluem para muitas coisas, que apresentam muitas propriedades complexas (CP 2.419). Exemplos de informação estão em muitos processos naturais (pense, por exemplo, na síntese dos elementos químicos que ocorre no núcleo das estrelas), e principalmente naqueles onde a vida e a inteligência se mostram especialmente ativos. A informação semiótica é, portanto, muito mais abrangente do que a informação algorítmica, que acabou sendo adotada como norma nas ciências desde que Claude Shannon (1948) publicou seu 
trabalho sobre a quantidade de incerteza associada à transmissão de sinais codificados num sistema probabilístico. Embora a informação semiótica também descreva a redução da redundância num sistema, ela está centrada no processo de significação - precisamente o que Shannon desconsidera em seu tratamento estatístico.

Abordando a questão de maneira um pouco mais formal, o conceito de informação de Peirce nasce como produto de duas quantidades: a extensão, também chamada de amplitude, é a quantidade relacionada ao universo dos objetos, reais ou fictícios, que o termo em questão é capaz de predicar; a compreensão, também chamada profundidade, é a quantidade relacionada às qualidades necessariamente envolvidas na definição do termo. Por exemplo, o termo composto "ser humano" tem uma extensão igual a todos os seres que podemos indicar (apontar ou denotar) como pertencentes à humanidade. A profundidade do termo "ser humano" corresponde a todas as qualidades que são universais de todos esses seres que podemos denotar, tais como: racionais, mortais, bípedes, mamíferos etc.

Ora, na tradição da lógica empirista era ponto pacífico que todo aumento de profundidade corresponde a um decréscimo na amplitude, e vice-versa. Ou seja, se reduzimos drasticamente a amplitude do "ser humano" até focar num espécime particular, veremos que o número de propriedades se expande proporcionalmente: um indivíduo humano é determinado por ser racional, bípede, mas também por predicados particulares como a cor de sua pele, de seus cabelos, de seus olhos, sua filiação, sua naturalidade, seu gênero, sua altura e assim por diante até que o indivíduo seja completamente denotado em todas as suas qualidades intrínsecas. Inversamente, na medida em que ampliamos a amplitude do termo, 
observamos que essas qualidades particulares deixam de ser aplicáveis até que, na máxima amplitude possível, voltamos a ter apenas os predicados mais gerais tais como racional, bípede e mamífero.

No entanto, Peirce descobriu que além dessas duas quantidades tradicionais há uma terceira, que corresponde ao crescimento, seja da amplitude, seja da profundidade, sem que haja um decréscimo da outra. Arqueólogos e antropólogos podem descobrir, por exemplo, que "ser humano" se refere também a grupos humanoides que viveram em regiões isoladas do planeta e que desapareceram há centenas de milhares de anos. Teremos aumentado a extensão do termo e, portanto, também a informação que contém. Por outro lado, podemos descobrir que seres humanos são capazes de se adaptar a condições climáticas extremas, expressando propriedades até então desconhecidas. Nesse caso, a descoberta dessas propriedades humanas terá ampliado a profundidade do termo e, portanto, também a informação que possuímos a seu respeito. A conclusão é de que, sem que houvesse informação, jamais descobriríamos nada de novo sobre qualquer coisa, pois a simples relação entre amplitude e profundidade produz aprendizado, crescimento e desenvolvimento.

A informação semiótica é importante na teoria geral dos signos de Peirce porque conecta os processos percepção aos de significação. De fato, uma das proposições que sustentam o método pragmatista peirceano é justamente a de que toda informação que possuímos deve entrar pelas portas da percepção, apresentar-se nas vestes de uma crença ou hábito mental e sair pelas portas da ação propositada. A consequência dessa fórmula é a seguinte: a informação que se revela pelo aumento da amplitude ou da profundidade deve entrar em nossas cognições por meio dos julgamentos perceptivos, para então 
ser compartilhada numa comunidade por meio da comunicação. $O$ conceito de crença é importante porque implica a capacidade que a informação tem de produzir consequências na realidade de uma sociedade. Não há informação neutra, desconectada das crenças socialmente compartilhadas. Por isso, quando procura matematizar a informação semiótica, Peirce se concentra na medida da intensidade das nossas crenças, e não no cálculo da entropia. Ele descarta, portanto, a probabilidade pura e adota o conceito de chance (CP 2.676).

Por exemplo, ao lançarmos uma moeda para decidir aleatoriamente entre duas possibilidades, temos a probabilidade de $1 / 2$ de o resultado sair cara, e a mesma probabilidade de $1 / 2$ de sair coroa. A chance de sair cara ou coroa num lance apenas, porém, é de 1/1. Em 100 lances, poderíamos ter algo como 48/52 para cara/coroa, o que é aceitável, mas ficaríamos desconfiados da neutralidade da moeda usada se o resultado fosse 25/75 para cara/coroa. Diante de um resultado assim, desenvolveríamos a crença de que a chance de o próximo lance dar cara seria de $1 / 3$ (e não mais $1 / 1$ ), o que contraria a crença de que a moeda usada é justa. Ou seja, nossa crença de que uma moeda particular é um método justo de escolha aleatória se baseia na observação dos resultados colhidos no tempo. Matematicamente, a crença na justiça de uma moeda (ou seja, que ela não foi adulterada ou está viciada para produzir mais caras do que coroas, ou vice-versa) depende do logaritmo da chance expressa nos resultados observados. Essa quantidade revela o que "seria", ou "aconteceria", se a moeda fosse usada como método aleatório de escolha. 0 predicado "justo", que faz parte da compreensão lógica do termo "esta moeda usada para decidir aleatoriamente uma escolha binária", é abandonado pelo seu inverso, "injusto", produzindo 
uma informação altamente significativa ${ }^{3}$. Essa informação vai ter consequências práticas e influenciar ações futuras, o que é a essência do significado.

\section{Sensações são o "ventre" da informação}

A informação brota da percepção como aumento da profundidade (compreensão), como experiência sentida, como interpretação particular. Sensações são, portanto, inferências sintéticas vinculadas a consciências individualizadas, a corpos particulares cognitivamente situados, capazes de substituir o feixe emaranhado das qualidades de sentimentos (predicados sutis e complexos) por predicados mais simples, tais como o sentimento de prazer ou de desprazer. Por outro lado, a generalização das sensações particulares vividas por cada um de nós, por meio da comunicação, produz o fundamento comum (common ground) de sentimentos compartilhados que une os participantes nos processos de comunicação no que Peirce chama de commens: uma mentalidade coletiva, contínua, resultante da fusão das mentes envolvidas na comunicação.

A produção de interpretantes finais gerais, tais como crenças ou hábitos mentais, é o caminho natural da causação comunicativa: na medida em que essas informações geradas pelas sensações corporais são comunicadas entre intérpretes, vemos que elas perdem sua intensidade original e ganham generalidade, ou seja, aumentam sua amplitude e se tornam mais complexas, gerando cultura. É o processo de comunicação, por meio de signos, das formas produzidas na percepção, que ga- 
rante o aumento da informação numa sociedade em comunicação. E é a conaturalidade entre os processos naturais e os processos mentais de causação que resolve o enigma da compreensão dos significados do signo. 0 signo não cria a significação, mas é a significação que se corporifica em signos particulares, que cumprem a função de meios de transmissão da informação, aumentando a razoabilidade, não nesta ou naquela mente particular, ou em qualquer número finito de mentes particulares, mas na mentalidade que permeia e une todos os que participam do processo de comunicação.

Dessa maneira, a realidade deve ser compreendida como aquilo que seria representado na opinião virtualmente última - e, portanto, verdadeira - que uma comunidade ideal de pesquisadores teria se dispusesse de todo o tempo e recursos para levar adiante a pesquisa. Isso significa que a realidade depende de uma representação geral, ou simbólica, que permanece sempre no condicional futuro (vago e indeterminado). Um símbolo, por sua vez, é um signo que tem o poder de determinar um interpretante geral, ou argumento, que se instancia num conjunto potencialmente infinito de proposições, cada qual revelando uma certa opinião, ou crença, sobre algum aspecto da realidade última. 0 processo de produção do conhecimento e de criação de cultura depende, portanto, da contínua generalização dos meios de comunicação onde a semiose ocorre, impulsionando o aumento da complexidade e do crescimento da informação no conjunto das mentes interpretantes, unidas pelo propósito comum da busca da verdade.

Temos em Peirce, portanto, uma metafísica que depende de uma concepção lógica, a da semiose como ação da mente, e a da mente como processo de causação que estrutura a realidade. Já vimos, porém, que o alicerce da lógica peirceana está calcado na sua teoria das categorias e na sua teoria matemática 
do contínuo, em que as três categorias se fundiriam no esquema geral do fluxo da causação, ou no esquema do tempo que viabiliza a ação da mente a partir da semiose. A conclusão de Peirce é que a solução do problema da realidade e da verdade depende de postularmos uma doutrina do contínuo, que ele denominou sinequismo (do grego sineche), bem como de seus corolários inevitáveis: a de que existe acaso absoluto como propulsor de toda originalidade que experimentamos - como a irrepetibilidade e irreversibilidade dos fenômenos - chamado de tiquismo (em grego, tiké significa acaso); e a de que todo conhecimento é provisório e falível, dependendo sempre das significações produzidas ao longo da comunicação entre as mentes interpretantes (doutrina chamada de falibilismo).

O pragmatismo peirceano é simplesmente a aplicação do sinequismo e seus corolários. Não é uma filosofia propriamente, mas um método que garante que a aceitação de hipóteses plausíveis (e o descarte de ideias que se mostram insuficientes por não se coadunarem com a experiência), e a disposição de continuar no processo de busca enquanto a curiosidade não for totalmente satisfeita. Poder-se-ia inclusive afirmar que o método pragmatista é um método baseado na comunicação, pois só é possível aumentar o conhecimento internalizado por um sistema se ele estiver em comunicação com algo que lhe forneça a necessária informação. Numa conversa cotidiana entre amigos, num bate-papo numa rede social ou entre professor e alunos numa sala de aula, vemos que a troca de signos permite que certos objetos da familiaridade entre os comunicantes sejam indicados, produzindo algum tipo de experiência capaz de gerar informação. O signo é o meio pelo qual a informação se manifesta na realidade. 


\section{O signo triádico e a negação da intuição cartesiana}

A teoria triádica dos signos de Peirce começa a se desenvolver já nos primeiros artigos publicados por ele, entre 1868 e 1871. O primeiro deles, que muitos scholars consideram a mais importante contribuição de Peirce para a filosofia, foi o "Nova Lista". Nele, Peirce articula uma revisão das tábuas de categorias de Aristóteles e Kant, expondo pela primeira vez sua ontologia tripartite. Nos dois anos seguintes (1868 e 1869), Peirce publica três outros artigos no Journal of Speculative Philosophy, hoje referidos como a "série sobre a cognição". Ele mantém sua preocupação com a origem do conhecimento, mas agora se propõe a apresentar uma alternativa para a gnosiologia cartesiana. Peirce refuta duramente a ideia de que o conhecimento se funda sobre uma dúvida artificial, como é o caso de cogito. Em vez disso, defende que a pesquisa comece com uma dúvida genuína sobre o mundo, procurando a resposta sem que tenhamos que nos despir de nossos preconceitos, mas corrigindo-os ao longo da própria pesquisa.

A disputa entre nominalismo e realismo faz o pano de fundo desses textos. Ela é uma derivação da polêmica "questão dos universais" que vem dividindo filósofos desde a Antiguidade Clássica. Grosso modo, quem acredita que os conceitos são apenas nomes que criamos para subsumir as impressões dos sentidos num conceito geral, é considerado um nominalista. Os realistas, por outro lado, são aqueles que acreditam que os universais, na forma de leis e potencialidades, existem efetivamente na realidade, determinando-a independentemente do que pensemos a respeito dela. Se o nomimalismo estiver certo, estamos condenados ao individualismo, pois 
cada um de nós desenvolverá suas próprias concepções sobre o mundo; mas se o realismo estiver certo, apenas a união dos esforços de todas as mentes poderá formar um conceito verdadeiro sobre a realidade. 0 nominalismo conduz ao solipsismo, mas o realismo abre as portas para o pragmatismo e para a comunicação como necessidade epistemológica para a produção do conhecimento numa comunidade virtual de interpretantes.

Essas duas grandes correntes tiveram várias ramificações, inclusive com doutrinas que procuravam uma via de meio entre os extremos que representam, como o transcendentalismo de Kant. Peirce foi um nominalista assumido na juventude, mas mudou de opinião ao longo de sua vida e chegou à maturidade proclamando-se um realista extremado. No entanto, o fato de Peirce ter refutado o nominalismo não significa que tivesse se tornado anti-idealista sob todos os aspectos. Como vimos ao citarmos seu conceito de informação, enquanto deva ser considerado um realista no campo da lógica, Peirce também foi um defensor do idealismo objetivo na metafísica. É por isso que alguns preferem dizer que Peirce desenvolveu um idealismo-realismo sui generis.

O "Nova Lista", porém, tem traços ainda nominalistas (como o próprio Peirce reconheceria ao fazer uma autocrítica de sua produção intelectual a partir de 1905). Nele, o elemento básico que condensa o conhecimento sobre o mundo é chamado de representação - uma manifestação mental que faz a ponte entre a realidade e o intelecto. Tudo começa com a síntese das impressões dos sentidos, em que a mente cria conceitos gerais por um processo de comparação. Revisando a tábua das categorias de Aristóteles e de Kant, Peirce propõe que aquelas presentes a priori na mente durante essa tarefa podem ser divididas em dois grandes grupos: ser e substân- 
cia. Enquanto a substância permanece incognoscível, no sentido transcendental kantiano, o ser pode ser representado de três maneiras que refletem possíveis tipos de comparação: qualidade (quando a comparação se refere a um fundamento, ou ground), relação ${ }^{4}$ (quando se refere a um correlato) e representação (quando se refere a um interpretante).

Essa mesma triadicidade é aplicada em seguida à representação, dando origem ao que Peirce chama então de semelhanças, índices e símbolos. 0 termo representação usado no "Nova Lista" equivale ao que, mais tarde, Peirce definiria como a relação entre signo, objeto e interpretante. Existe, portanto, uma relação triádica indecomponível no signo: o significado não se dá na relação entre o signo e o objeto apenas, como afirmavam a maior parte das teorias dos signos anteriores, mas exige um terceiro correlato. Esse novo elemento é o interpretante, visto como o efeito produzido na mente pelo signo e, portanto, um outro signo. Nessa época, convém esclarecer, Peirce ainda via a representação restrita ao pensamento - uma espécie de discurso mental internalizado, baseado apenas sobre conceitos gerais dependentes da linguagem.

Nos três artigos seguintes ao "Nova Lista", destinados especificamente ao problema da cognição, Peirce eliminou a bipartição entre ser e substância, assumindo a tese de que não existe o objeto incognoscível apresentado por Kant em sua filosofia transcendental. 0 propósito central desses artigos é combater a ideia de que a cognição humana deve começar com uma dúvida, como afirmara Descartes. Para Peirce, a cognição é um processo dinâmico que não tem um ponto inicial de partida, mas acontece in media res. Nós devemos partir de nossos preconceitos, ou ideias imperfeitas e, lentamente, por

4 Mais tarde, Peirce substituirá "relação" por "reação" para enfatizar o aspecto de "choque cego" da segunda categoria. 
meio de um processo contínuo de inferências e testes de hipóteses na realidade, tecer uma argumentação que não seja uma corrente linear, como defendeu Descartes (e que não pode ser mais forte do que seu elo mais fraco), mas um cabo de fibras que podem ser cada uma delas fina e sutil, desde que sejam tão numerosas e intimamente conectadas de forma a garantir a força de todo o argumento.

Para Peirce, o "trem do pensamento" é uma concatenação de conceitos que não possui começo nem fim, mas a fusão de uns nos outros, de maneira que a interpretação surja como produto desse processo. Um pensamento é um signo que representa um pensamento anterior (o seu objeto) enquanto é interpretado por um pensamento subsequente (o seu interpretante), e assim sucessivamente ad infinitum (SHORT, 2004, p. 9). A semiose, a ação do signo, assume um papel fundamental na busca da pragmática da verdade, que é esperada como o resultado final do processo. Embora esta seja uma série infinita, não precisa arrastar-se para sempre porque as inferências ocorrem em instantes infinitesimais. Peirce recorre ao paradoxo da Zeno sobre a corrida entre Aquiles e a tartaruga para mostrar que a ideia de uma série infinita de interpretantes não implica uma semiose interminável, pois, assim como Aquiles acabará por alcançar a tartaruga, a série infinita de inferências produzirá um resultado cognitivo determinado.

Numa resenha crítica de 1871, dedicada à reedição da obra do bispo George Berkley (um conhecido nominalista que viveu entre 1685 e 1753), Peirce dá mais um passo na direção de um realismo cada vez mais decidido, embora ainda distante do tipo que viria a assumir nas décadas seguintes. Faltava-lhe, ainda, uma noção clara do papel da segundidade como expressão de uma realidade que existe fora da mente, e não como construto mental feito a partir da síntese de signos- 
-pensamentos. Esse será o papel assumido pelo índice em sua semiótica madura. Apesar de já ter feito a tripartição do signo em semelhanças, índices e símbolos, Peirce ainda afirma que o lógico deve considerar apenas os tipos de representação que surgem do símbolo. Aquilo que é exterior à mente não deve, portanto, interessar à lógica.

Esse traço nominalista perdurou por toda a década de 1870 e ainda influenciou o texto inaugural do pragmatismo, "Como Clarear Nossas Ideias", publicado em 1878. Segundo Houser (2002), com esse artigo, Peirce pretendia "que o pragmatismo fosse um melhoramento do método de Descartes de classificar ideias por meio do teste de sua clareza e distinção". 0 pragmatismo aparece restrito a um método para tornar claros os conceitos, apenas relacionando o significado às consequências implicadas na sua aceitação. Seu nominalismo é explícito quando Peirce diz aos leitores que nada nos impede de afirmar que "todos os corpos duros permanecem perfeitamente macios até que os toquemos" (EP, 1:132), ou seja, que a ideia de solidez é algo que só existe nas nossas mentes e nada tem a ver com a realidade das coisas.

\section{A descoberta da quantificação e a semiose do mundo natural}

No restante da década de 1870 , Peirce abandonou a disputa nominalismo-realismo e dedicou muitos esforços à promoção de seu pragmatismo nas reuniões do Clube Metafísico de Cambridge, do qual era sócio fundador, e à construção de um sistema lógico algébrico inspirado na recém-publicada obra de Boole. A colheita de dez anos de estudos começou a aparecer em 1883, quando Peirce e o mais brilhante de seus 
alunos na Universidade Johns Hopkins, Oscar Mitchell, concluíram que a lógica precisava de índices para expressar a ideia de quantificação (SHORT, 2004,12). Em outras palavras, era preciso usar seletivos tais como "algum" e "todo" para indicar o sujeito de um predicado geral. Essa descoberta foi feita independentemente de Frege, cujo trabalho permanecia desconhecido. Também nessa época, Peirce estudou a obra do matemático George Cantor sobre o contínuo (HOUSER, 1998, p. XXVII), que o inspirou a desenvolver uma topologia e uma teoria dos conjuntos para enfrentar a questão do contínuo.

Esses avanços produziram uma reformulação em todo seu sistema filosófico, e tiveram repercussão também na semiótica. A quantificação a partir de índices, por exemplo, faz Peirce reconhecer que o mundo exterior possui uma realidade e que a lógica precisa aprender essa lição. Num importante texto sobre a álgebra da lógica, de 1885, Peirce fez a ponte entre sua descoberta dos quantificadores lógicos e sua semiótica, afirmando que uma notação lógica completa deveria possuir signos gerais ou convencionais (símbolos), quantificadores ou seletivos da mesma espécie que os pronomes demonstrativos (índices) e signos de semelhança (ícones). Os índices deixavam de ser coadjuvantes no processo do conhecimento e da representação.

0 efeito mais importante da descoberta do papel do índice foi o abandono da tese anterior de que toda cognição deve ser precedida por outra cognição, ad infinitum (o "trem do pensamento"). Como um alfinete que usamos para indicar um lugar no mapa, o índice tem a capacidade de selecionar a ocorrência individual de um geral, que então passa a ser o sujeito de uma proposição. E como o índice se conecta existencialmente com o assunto que denota, então também a proposição se conecta a esse assunto. Assim, uma cognição não 
precisa ser necessariamente encadeada a outra. Junto com o novo papel reservado aos índices, Peirce refinou a terminologia de sua semiótica. 0 que antes era chamado de "semelhança", "cópia" e "imagens", agora passará a ser chamado de ícone. E a hipótese que, como vimos, havia sido apresentada nos artigos de 1870, agora recebe o nome de abdução ou, às vezes, de retrodução.

Também nessa época, Peirce adotou a noção de degeneração, emprestada da geometria projetiva, para aplicá-la à lógica das relações. Assim, ícones, índices e símbolos passam a ser derivados dos três diferentes tipos de relação que um signo pode ter com seu objeto, de acordo com a teoria das categorias. 0 ícone relaciona-se de forma monádica, por semelhança, quando signo e objeto possuem a mesma propriedade, ou por exemplificação, quando o objeto é uma propriedade que o signo possui. 0 índice apresenta uma relação diádica com seu objeto, por possuir uma conexão real com ele. Apenas o símbolo possui uma relação genuinamente triádica e, portanto, intrinsecamente lógica, tendo um poder de representação que se dá por convenção arbitrária (CP, 2.274).

Ao mesmo tempo em que estreitava o vínculo entre a semiótica e a categoriologia, Peirce alimentou, em 1887, uma polêmica contra a visão mecanicista do universo de Herbert Spencer (CP, 1.33). Segundo Peirce, a causalidade meramente mecânica, do tipo causa-efeito não pode explicar os fenômenos de crescimento e desenvolvimento presentes no universo. Havia a necessidade, portanto, de um terceiro elemento "virtual", no sentido de ter uma virtude que se efetivará no futuro. Em outras palavras, o universo não é mecanicista, mas teleológico e guiado por propósitos. Em vez da causalidade diádica, precisamos de uma causação triádica.

Essa concepção de causação final também foi o primeiro 
passo para a criação de uma metafísica semiótica, em que a semiose fosse considerada a evolução teleológica de uma realidade composta por signos - visão que só se efetivaria duas décadas mais tarde, em 1907. Por volta de 1888, Peirce afirmava que havia apenas três elementos ativos no mundo: primeiro, o acaso; segundo, a lei; e terceiro, a capacidade de formar hábitos. Embora não houvesse ainda uma identificação explícita entre esses três estágios ontológicos e as tricotomias que derivam os signos, Peirce caminhava nessa direção.

Em meados da década de 1890 (e como decorrência natural de seus estudos sobre o papel da segundidade na lógica), Peirce proclamou sua aceitação daquilo que o escolástico medieval Duns Scotus definia como haecceitas, ou o puro existente hic et nunc, sem nenhuma qualidade ou generalidade (Houser, 1992, p. XXVII). 0 choque de realidade traz mudanças na sua maneira de ver o pragmatismo: a realidade que deixa de ser considerada aquilo que a última opinião do processo de pesquisa efetivamente revelará para ser considerada uma esperança de acordo final que estimula a comunidade dos pesquisadores a continuar a busca. Em outras palavras, a realidade tem um modo condicional: aquilo que "seria" revelado se todos os esforços possíveis de pesquisa fossem realizados.

Em 1895 e 1896, Peirce escreveu vários esboços de capítulos para um livro de lógica que jamais foi publicado. Neles, mostrou mais uma vez as relações íntimas entre lógica e semiótica, explicitamente comparando a semiose com o processo de raciocínio mental. Uma proposição, por exemplo, deve sempre conter ícones e índices. Além disso, a abdução ganha um destaque cada vez maior, sendo considerada o tipo de raciocínio capaz de oferecer conhecimento novo e, portanto, essencial para os desenvolvimentos da lógica e das ciências em geral. 
Peirce explica a abdução como uma forma de instinto baseado na afinidade de nossa mente com a natureza, enfatizando que a lógica do pragmatismo é essencialmente abdutiva e, portanto, vinculada a processos não racionais e, provavelmente, não-conscientes da mente. Enquanto alargava o campo da semiótica, Peirce passou a distinguir dois sentidos para a lógica: um mais tradicional, restrito às formas de argumento e suas condições de verdade; e outro mais extenso, em que vislumbrava uma teoria geral dos signos que ultrapassasse os limites da lógica tradicional para penetrar na antecâmara da razão.

\section{Os estudos da percepção e a classificação de 1903}

A terceira fase do percurso no caminho de uma teoria semiótica da comunicação começa quando Peirce dá mais um passo na direção do realismo lógico ao aceitar, a partir de 1896, o universo das possibilidades como presente ontologicamente no mundo (SHORT, 2004, p. 15). Em 1987, Peirce passa a defender um tipo de realismo que lembra o de Aristóteles, mas com ênfase especial na haecceitas de Scotus. As três categorias - possibilidade, reação e mediação - são consideradas por Peirce completas e irredutíveis, recebendo finalmente os nomes pelas quais são hoje conhecidas: primeiridade, segundidade e terceiridade. Essa nova posição levou Peirce a retomar seus estudos sobre a cognição, feitos anteriormente sob forte influência kantiana, para agora apresentá-los na nova roupagem realista de sua filosofia.

No ano seguinte, em 1898, o velho amigo das reuniões filosóficas do Clube Metafísico, William James (considerado agora um dos mais proeminentes intelectuais norte-america- 
nos), tornou público que Peirce era o criador da filosofia do pragmatismo. 0 alvoroço em torno de Peirce que se seguiu a este anúncio produziu nele uma dupla reação: de um lado, passou a criticar aberta e acidamente aqueles que usavam o termo pragmatismo fora de seu escopo essencialmente lógico, sem poupar nem mesmo o próprio James, acusado de manchar o pragmatismo com seu psicologismo de pouco rigor lógico. De outro lado, assumiu a missão de revisar os fundamentos do pragmatismo, oferecendo-lhe uma prova definitiva dentro do âmbito original de "método para clarear conceitos". Peirce achava possível fazer isso a partir dos estudos em lógica e semiótica que havia realizado após a primeira formulação da máxima pragmática.

O começo da década de 1900 reacendeu em Peirce o desejo de publicar em livro suas ideias e resultados obtidos no campo da lógica, principalmente em relação à topologia, à modalidade e ao desenvolvimento da sintaxe lógica dos grafos existenciais. Ele chegou a produzir um resumo dos temas que abordaria, que hoje é considerado a melhor exposição da arquitetura das ideias de Peirce feito de sua própria lavra (CP, 4.227-322). Uma vez mais, porém, sua esperança de sistematizar as contribuições que fizera ao longo dos anos passados num grande volume de lógica ficou frustrada por falta de apoio financeiro. Enquanto o processo de decisão sobre seu livro se arrastava, Peirce retomou sua teoria dos signos, procurando nela a desejada prova do pragmatismo. Ao mesmo tempo, William James o convidou para duas séries de conferências a serem oferecidas em 1903: uma em Harvard, dedicada ao pragmatismo, e outra no Instituto Lowell, em Cambridge, voltada especificamente para a lógica.

0 resultado desse duplo estímulo foi uma revisão dos fundamentos de seu sistema filosófico e, como decorrência, 
uma revisão também de sua teoria dos signos. Em 1902, ao retomar seus artigos e manuscritos dedicados à discussão da teoria da evolução e de sua relação com as leis da física, produzidos entre 1891 e 1898, Peirce conclui que o propósito que guia a evolução das espécies e das leis do universo não pode estar baseado na consciência humana, mas que, ao contrário, nossa consciência é que deve ser entendida como produto de um movimento teleológico na direção de um propósito. Esta é, em resumo, a tese aristotélica da causa final, que Peirce adota como fundamento da evolução do signo, ou semiose.

Peirce concluiu que lógica e semiótica são animadas pelo mesmo princípio guia (leading principle) (CP, 7.461), podendo ser tomadas como sinônimos. Tomando emprestada a divisão medieval das artes liberais em gramática, lógica e retórica, Peirce, pela primeira vez, anuncia sua conhecida repartição da semiótica em gramática especulativa, lógica crítica e retórica.

Ainda no âmbito das conferências sobre o pragmatismo, havia a necessidade de abordar mais uma vez o problema da origem do conhecimento, que Peirce agora ataca sob o ponto de vista da percepção, aproveitando seus estudos em quantificação e no papel do índice na fundação da lógica. Começando mais uma vez em 1902, Peirce desenvolve uma teoria da percepção nova, destinada a conjugar o realismo lógico com seu falibilismo e que terá sua primeira exposição nas palestras de Harvard, em março de 1903.

Peirce afirma que as primeiras premissas lógicas brotam no contato com a realidade na forma de juízos perceptivos. Isso não significa que esses juízos sejam intuições imanentistas - o que significaria render-se à tese cartesiana tão duramente combatida nos artigos sobre a cognição. Os juízos perceptivos são hipóteses da mesma natureza das abduções 
e, portanto, falíveis. Não podemos conhecer imediatamente a verdade das relações entre as coisas, mas há entre a razão das coisas e a nossa um mesmo fundamento lógico: o princípio da causação e do contínuo, que autoriza a crença de que nossas hipóteses, mais cedo ou mais tarde, se conformarão com a forma que rege os processos naturais.

\section{Os três correlatos do Syllabus}

Peirce produz em 1903 o mais próximo que temos de uma exposição sistemática de sua teoria dos signos. É uma brochura escrita para acompanhar uma série de palestras que deu no Instituto Lowell, em Cambridge, durante o mês de outubro de 1903, dedicadas principalmente à lógica. Ela é normalmente referida como Syllabus entre os comentadores, muitos dos quais a consideram a versão mais acabada de sua semiótica. Nela aparece, por exemplo, o famoso triângulo com dez classes de signos criados a partir de três divisões triádicas, e sua aplicação a variados aspectos da lógica.

De fato, a apresentação da classificação dos signos em dez classes sugere que, em algum momento entre as conferências de Harvard e a redação do Syllabus para as conferências do Instituto Lowell, oferecidas em outubro de 1903, Peirce teve um insight que mudou a estrutura de sua classificação dos signos. Segundo Freadman (2004), essa mudança é evidente na maneira como a relação sígnica se complica se compararmos com a que Peirce vinha usando até então: pela primeira vez, os signos são apresentados como classes compostas de três correlatos.

O signo é aqui definido como um primeiro correlato de uma relação triádica indecomponível, que compreende tam- 
bém aquilo que o signo professa representar (o segundo correlato, ou seu objeto), e o efeito produzido pelo signo, chamado de seu interpretante (ou terceiro correlato). No primeiro correlato, o signo pode ser uma mera possibilidade (batizado de quali-signo), um objeto ou evento singular (um sin-signo) ou um tipo de lei governando suas réplicas (legi-signo). No segundo correlato, que considera a relação do signo e seu objeto, os signos podem ser os já conhecidos ícones, índices e símbolos. No terceiro correlato, finalmente, os signos podem ser remas (o genérico para os termos lógicos), dici-signos (o genérico das proposições) e argumentos (o genérico dos silogismos ou inferências).

Seguindo uma ordem de implicação material, em que o primeiro correlato determina o terceiro por meio do segundo, Peirce chega então a dez classes de signos que ele chama de genuínos e os classifica distribuindo-os numa pirâmide invertida. Além disso, Peirce discorre sobre algumas das possíveis degenerações que os tipos e classes de signos podem sofrer e sua utilidade para a lógica. Dada a audiência do Instituto Lowell, não há dúvida que o Syllabus e seus manuscritos preparatórios refletem a preocupação de Peirce em explicitar sua semiótica como um sinônimo para a lógica concebida de acordo com os princípios da matemática. Esse foco na vinculação entre semiótica e lógica parece ter produzido uma mudança radical na maneira como Peirce concebia as relações sígnicas. Isso está de acordo com o desenvolvimento que imprimiu à sua teoria dos signos nos anos seguintes, que já não retomam mais os termos e conceitos usados antes de 1903, mas na verdade enfatizam e desdobram os resultados de sua pesquisa naquele ano.

Ainda em 1903, outro evento importante na vida intelectual de Peirce, principalmente em relação à teoria dos signos, 
foi o início da correspondência com Victoria Lady Welby. Peirce havia revisado favoravelmente o livro What Is Meaning?, de Welby, abrindo as portas para um contato por correspondência que durou até 1911, um ano antes da morte de Welby. As cartas trocadas entre eles mostram as enormes transformações que Peirce deu à sua teoria na fase final de sua vida. Alguns scholars acreditam, inclusive, que Welby teve uma influência decisiva nessa fase, o que explicaria, ao menos em parte, por que Peirce dedica tantos esforços para desvendar os tipos de interpretantes presentes na semiose (SANTAELLA, 2004). Em 1904, por exemplo, Peirce já anunciava a necessidade de tricotomizar o interpretante do signo de acordo com as categorias criando, respectivamente, os termos emocional, energético e lógico para qualificar os três estados ontológicos que o interpretante pode assumir.

Depois de fundar a origem do conhecimento na percepção e de desenvolver uma taxonomia dos signos que naquele momento lhe parecia aceitável para lidar com os problemas da lógica, Peirce voltou sua atenção para o terceiro ramo da semiótica, o da retórica. Sua intenção era abordar mais uma vez os efeitos esperados pela ação do signo sobre o interpretante, mas agora vendo-os a partir dos resultados conseguidos dos últimos anos. Em 1904, por exemplo, Peirce afirma que a representação tem o poder de causar fatos reais (EP, 2.300), e que os interpretantes do signo não precisam ser obrigatoriamente conceitos, como pregava sua versão ainda intelectualista da semiose como encadeamento de pensamentos, mas também podem ser sentimentos e efeitos físicos. Dessa forma, adianta a divisão dos interpretantes em emocionais, energéticos e lógicos, que se tornará explícita em 1907. 


\section{A multiplicação das tricotomias e a noção de interpretante ultimal}

A última fase da semiótica de Peirce é infelizmente a menos conhecida e compreendida, porque nela estão as bases lógicas de uma teoria realista da comunicação, capaz de oferecer um repertório de conceitos que, se mais bem conhecidos, ajudariam imensamente no estudo de fenômenos contemporâneos da comunicação, como a das redes sociais virtuais, a ubiquidade dos dispositivos móveis e a aproximação entre os estudos de aumento da inteligência e da inteligência artificial.

Isso se deve, em parte, ao fato de ela representar uma reviravolta na maneira de Peirce entender sua teoria dos signos, provavelmente motivada pela sua preocupação em integrar a semiótica, o pragmatismo e a cosmologia. Enquanto aparava arestas para ajustar o engate de uma disciplina na outra, fazia constantes alterações, muitas tentativamente, produzindo versões que depois eram descartadas. Seus cadernos de lógica dessa época estão cheios de rascunhos de classificações, introduções de termos novos, uma profusão de divisões triádicas e vários desenhos geométricos, principalmente triângulos, usados heuristicamente para explorar e evidenciar relações. Muitos desses rascunhos são contraditórios e, embora estejam datados, Peirce não nos autoriza a considerar os posteriores como versões necessariamente aprimoradas. Ao atingir um impasse, frequentemente retomava classificações antigas, às vezes produzidas muitos anos antes, abandonando os resultados mais recentes.

Em 1905, Peirce demonstra já possuir sua noção realista da terceiridade, construída como um condicional futuro, ou would be, que não pode ser reduzido a qualquer série de instâncias particulares. Ele corrige explicitamente sua opi- 
nião de 1878 sobre a dureza dos objetos e declara que cabe ao pragmatismo insistir sobre a realidade das potencialidades gerais na natureza (SHORT, 2004, p. 15). A aceitação da realidade das leis da natureza, consideradas agora como hábitos análogos às crenças da mente, estimulou-o a aproximar a semiótica, já estendida para abranger os sintomas e sinais físicos, do pragmatismo, cujo coração estava precisamente na noção de hábito de conduta.

No terceiro de uma série produzida para a revista filosófica The Monist, Peirce fez a primeira tentativa de extrair da semiótica uma prova para o pragmatismo - ou pragmaticismo, como ele eventualmente passou a chamar sua filosofia numa tentativa de dissociá-la da versão propagada por William James e seus discípulos, que Peirce acusava de subjetivista e centrada demasiadamente em resultados práticos. A verdade, porém, é que o termo pragmaticismo nunca se popularizou realmente, e o próprio Peirce voltaria a chamar sua doutrina de pragmatismo nos anos posteriores.

Para combater o nominalismo que contaminava as versões populares do pragmatismo, Peirce enfatizava que sua prova do pragmatismo seria também uma prova do realismo, em que a verdade deveria ser considerada como a opinião final da pesquisa feita por uma comunidade idealmente infinita e honestamente dedicada a essa busca. 0 real seria o objeto imediato dessa representação verdadeira.

No curso dessas pesquisas, Peirce descobriu que sua lógica, vista agora tal qual semiótica, poderia ser apresentada por meio da utilização de gráficos visuais - batizados por ele de grafos existenciais - capazes de realizar de forma bem mais concisa e direta a manipulação dos signos lógicos. Apesar de apresentar duas versões bastante desenvolvidas desse sistema, Peirce tampouco conseguiu completá-lo da maneira 
que havia desejado, provavelmente barrado por dificuldades em representar a ideia de contínuo. De qualquer forma, sua pesquisa sobre os grafos existenciais deu início a um novo ramo da lógica que, nos últimos anos, tem produzido resultados promissores.

Entre 1905 e 1906, Peirce trabalhou intensamente sobre sua classificação dos signos, como ele mesmo afirma numa carta a Lady Welby. Suas pesquisas o convenceram de que uma classificação completa exigiria pelo menos dez tricotomias que, se relacionadas livremente, poderiam atingir uma cifra espantosa de 59.049 classes de signos (CP, 1.291), mas que, considerando as limitações lógico-matemáticas impostas na sua geração, o total delas deveria se restringir a 66. Peirce também afirma que ter encontrado a necessidade de distinguir entre dois objetos semióticos: o imediato, presente no interior do signo, e o dinâmico, que permanece fora do signo; além de três tipos de interpretantes - aqui batizados de intencional, efetivo e comunicacional -, mas que depois seriam chamados de imediato, dinâmico e final.

Não há dúvida que essa proliferação de interpretantes reflete uma crescente preocupação de Peirce com o terceiro ramo da semiótica, aquele da retórica. A metodêutica passa a ser considerada a retórica num sentido estreito, enquanto a retórica assume o sentido mais geral de comunicação (BERGMAN, 2000, p. 246-247). Ou seja, no âmbito mais restrito da pesquisa cientificamente conduzida, as questões do método, ou metodêutica, revelam como a ciência se constrói como linguagem especializada que compartilha o significado das descobertas no círculo dos interessados. A retórica, porém, vê a comunicação em sua máxima amplitude, e estuda os efeitos comunicativos em geral na produção e troca de sentidos culturalmente. 
Deduzindo as implicações de sua cosmologia cada vez mais pampsiquista, Peirce conclui que o processo de interpretação não acontece apenas no interior de mentes humanas. Ao contrário, é a existência de uma contínua interpretação dos signos no mundo que permite explicar a emergência da nossa inteligência. 0 universo está repleto de signos, se não for composto apenas por signos, e tentar descobrir a realidade, a "coisa real" atrás do véu dos signos, é algo ilusório. Como já vimos, ao aplicar essa visão de universo mental no campo da retórica, Peirce é levado a introduzir, ainda em 1906, a idéia de commens ou co-mente, um produto da comunicação ou "fusão" das mentes que trocam informação.

Na verdade, a co-mente não é apenas a fusão das mentes de uma comunidade idealmente infinita. Mais genericamente ainda, ela é o pressuposto para que o signo possa transferir a forma do objeto ao interpretante (HOUSER, 1998, p. XXX). Ela é a fusão entre signo, objeto e interpretante e signo no momento da comunicação, quando a informação é transmitida do objeto para o interpretante por meio do signo. 0 objeto assume a posição de um emissor (utterer), o interpretante a de um receptor (interpreter), o signo a de um meio (medium) e a mensagem a da forma ou ideia a ser transmitida.

Com a introdução do conceito de co-mente, Peirce estava a um pequeno passo de finalmente engatar sua semiótica de tons metafísicos ao pragmatismo. Só lhe faltava, para isso, eliminar a âncora intelectualista que ele havia colocado sobre sua filosofia ao afirmar que o interpretante de um conceito só pode ser um outro conceito. Essa barreira é finalmente quebrada em 1907, quando Peirce adota a ideia de interpretante lógico "último". Peirce compreende que o interpretante lógico último não poderia ser um outro conceito porque isso produziria uma série progressiva infinita - como já explicara em 
seus artigos sobre a cognição, da década de 1860. Para evitar a progressão ad infinitum, Peirce deu ao interpretante lógico o status de um hábito ou, quando a ocasião se faz necessária, ao efeito de mudança de um hábito produzido numa mente comunitária inteligente, em contínua transformação.

Em 1909, enquanto rascunhava um "sistema de lógica, considerado como semiótica”, Peirce afirma que o interpretante último não é a maneira como um conjunto finito de mentes efetivamente age sob a influência de um conceito, mas como qualquer mente "agiria" (would act) sob seu efeito uma modalização que se harmoniza finalmente com sua ideia de terceiridade presente na natureza, anunciada em 1906. 0 condicional futuro, o hábito que não se esgota em nenhuma de suas ocorrências ou, melhor ainda, a própria mudança de hábito no caminho da razoabilidade plena, passa a ser o propósito de seu pragmaticismo.

Se por um lado semiótica e pragmatismo aparecem de mãos dadas pelo conceito de hábito, por outro, essa união obriga Peirce a rever a força da máxima pragmática. Isso porque o hábito não se sustenta apenas sobre considerações lógicas, mas também exige considerações éticas e estéticas. Não deve surpreender, portanto, que Peirce passe cada vez mais a colocar a ética e estética como ciências normativas responsáveis, juntamente com a lógica, por controlar a conduta humana.

Ao buscar na teoria dos signos uma prova definitiva do pragmaticismo, Peirce acabou levando sua semiótica ao patamar máximo da transdisciplinaridade. Se o universo é repleto de signos, se não for composto exclusivamente por signos (CP, 5.448) como Peirce sustentou na fase final de suas pesquisas, então uma teoria unificada da realidade, se um dia for possível concebê-la, deverá ser necessariamente semiótica. 


\section{A semiótica como chave transdisciplinar}

Expresso em sua forma mais simples, o signo é alguma coisa que professa representar outra coisa de maneira a determinar um efeito, que é o resultado da representação. 0 importante aqui é a relação triádica entre algo que representa, algo que é representado e algo que se coloca como efeito dessa representação. Aquilo que o signo professa representar é seu objeto, que pode ter uma ampla ontologia: uma qualidade (cor, cheiro, sabor etc.), uma ideia abstrata, um objeto existente (um cachimbo, uma cadeira, uma pessoa etc.). 0 efeito produzido pela representação é chamado de interpretante. Não é necessário que o interpretante seja o efeito num intérprete humano e, mais geralmente ainda, sequer é necessário que o interpretante seja produzido por um ser vivo. Basta que subsista entre signo, objeto e interpretante uma relação lógica de natureza triádica, ainda que esta relação se mantenha como potencialidade à espera de atualização, talvez indefinidamente.

Sabemos, porém, que o signo não representa perfeitamente seu objeto. Uma representação perfeita implicaria uma identidade entre signo e objeto, o que produziria o colapso da significação em percepção imediata. Ou seja, o signo pode representar seu objeto apenas sob um ou alguns aspectos. Vimos, então, que o signo precisa de uma fundamentação (ground) que o autoriza a professar representar seu objeto. Há, portanto, um objeto externo ao signo, que Peirce chama de dinâmico, e a representação desse objeto dinâmico no interior do signo, chamado de imediato. 0 objeto imediato, por ser interno ao signo, está sempre num estado de potência, no sentido aristotélico da palavra. Pode-se dizer que o objeto imediato garante uma probabilidade de o signo ser interpretado como tal. 
Ainda que esteja sempre fora do signo, o objeto dinâmico não é uma entidade incognoscível, como o ding an sich, de Kant. Embora tenha a capacidade de determinar o caminho da semiose, orientando o signo em sua evolução na direção de um interpretante final, o objeto dinâmico é parte do mesmo fluxo de causação que produz o signo e, portanto, é naturalmente predicável pelo signo. Como ambos signo e objeto dinâmico, brotam das leis lógicas da natureza, não há entre eles incomensurabilidade, apenas separação lógica. 0 realismo de Peirce que, como vimos, sustenta-se sobre uma teoria da percepção imediata, dá garantias de que as qualidades imediatamente percebidas e incorporadas pelo signo seriam efetivamente as do objeto dinâmico, caso a semiose ocorresse em condições ideais.

Claro que o falibilismo inerente da semiose impede que o signo compreenda completamente seu objeto, mas o contínuo das leis de causação oferece um fundamento de predicação possível, que livra o objeto dinâmico da total ininteligibilidade, oferecendo, talvez, pouco mais do que uma esperança de que nossas cognições sejam bem justificadas, mas, ao mesmo tempo, mostrando que se não houvesse qualquer similaridade entre nossos conhecimentos e as leis da natureza, teríamos sucumbido no processo de evolução

Como o signo não é um ente estático, mas se mantém em contínua evolução na semiose, deve-se contemplar também a gama dos efeitos potenciais que ele carrega implicitamente, enquanto evolui. A esses efeitos potenciais chamamos de interpretantes imediatos. 0 interpretante imediato garante uma latitude de prováveis interpretações do signo. Se e quando essas prováveis interpretações se efetivarem, teremos a produção de interpretantes dinâmicos, que nada mais são do que efeitos efetivamente criados na realidade pela ação do signo. 
Por fim, todo signo tem um interpretante final, ou último, que revela no que o signo se transformaria, ao final do processo, se todas as suas potencialidades fossem desenvolvidas.

Ninguém duvida, por exemplo, que uma rocha localizada na superfície de marte e iluminada pelo sol estaria aquecida se sua temperatura fosse realmente medida. É uma consequência lógica de como o universo se organiza, independentemente da vontade de qualquer ser ou comunidade de seres interessados em estudar o comportamento dessa rocha. 0 aquecimento da rocha marciana é um signo in potentia da presença de uma fonte de calor incidindo sobre a rocha (o sol, muito provavelmente). Seu objeto imediato é calor do sol, que ela incorpora e que produz entre a rocha e sol um contínuo qualitativo. 0 interpretante imediato são todos os possíveis efeitos que o aquecimento da rocha poderia gerar em todos os cenários imagináveis.

Se e quando alguma mente inteligente encontrar essa pedra (um astronauta, por exemplo), notará que ela está quente e iluminada. 0 interpretante dinâmico é o efeito produzido pela rocha quente nessa eventual mente inteligente, que disso inferirá que alguma fonte de luz quente incide sobre ela, descobrindo, então, que ela está localizada numa região de Marte iluminada pelo sol. Esta informação, antes latente, terá sido manifestada, pois agora o astronauta sabe algo mais sobre o universo que o rodeia.

Vimos que, enquanto é determinado pelo objeto dinâmico, o signo determina interpretantes dinâmicos, que são os efeitos efetivamente produzidos no processo de significação. No caso da rocha marciana, a medição por um termômetro (colocado por um astronauta junto à rocha) do aumento de sua temperatura é um interpretante dinâmico, ou efeito efetivamente produzido pela rocha aquecida. Outro efeito dinâ- 
mico seria a observação do resultado da medição realizada pelo termômetro por parte do astronauta. Outro efeito dinâmico seria o registro dessa observação num bloco de notas. $\mathrm{E}$ assim sucessivamente. Por fim, o signo tem um interpretante final que, na sua maior generalidade, expressa o efeito último que o signo estaria destinado a produzir se as condições fossem ideais. No caso do aquecimento de nossa hipotética rocha, o interpretante final poderia ser uma nova descoberta científica produzida pela observação do fenômeno, aceita e compartilhada por toda a comunidade de intérpretes interessados, inclusive as lições estéticas e éticas implicadas por essa descoberta.

De nosso exemplo devemos constatar que, se a informação flui por toda parte, como têm demonstrado a física, a química e a biologia, devemos considerar a comunicação como um componente ontológico da realidade. Essa é a vanguarda da pesquisa em comunicação e semiótica, cujas possibilidades teóricas têm atraído pesquisadores de várias áreas científicas. A comunicação não é a mesma em todo canto, porém. É preciso estabelecer gradiente comunicacional que parta da transmissão de informação no nível da matéria, fortemente constrangida pelas leis da física (ou hábitos enrijecidos), para atingir as formas de comunicação mais livres e criativas, como a que ocorre entre seres vivos e, mais ainda, em seres inteligentes e dotados de consciência particular.

Essa era certamente a opinião de Peirce na última fase de sua produção intelectual. Em 1903, ele afirmou que o universo inteiro é um signo semelhante a uma pintura impressionista (CP, 5.119). Em 1905, escreveu que "um signo se conforma perfeitamente à definição de um medium de comunicação" 
(MS, 28355). Já em 1911, definiu o signo usando o jornal como exemplo: "se uma pessoa lê um item de notícia num jornal, seu primeiro efeito será provavelmente o de causar nessa mente o que pode convenientemente ser chamado de uma 'imagem' do objeto, sem que se faça qualquer julgamento sobre sua realidade" (MS, 670). Mas a pessoa em questão só pode compreender o que está escrito no jornal (ou nas telas que hoje fazem a informação circular nas redes sociais, se quisermos), se ela estiver imersa no fluxo de causação e crescimento da informação que une a totalidade do universo inteligível. É esse common ground que empresta inteligibilidade ao que está escrito nas páginas do jornal, ao que o redator escreveu para ser publicado, ao que o repórter apurou para enviar ao redator, ao fato apurado nas suas consequências lógicas e, assim, sucessivamente, sem que jamais consigamos descascar completamente a "cebola" da semiose e da produção de significados.

\section{Conclusão}

A teoria semiótica da comunicação proposta por Peirce é realista e monista, baseada numa metafísica que se afirma a partir da análise das relações lógicas entre os aspectos do signo, tendo a matemática e a fenomenologia como fonte de suas primeiras premissas. Ela não admite o dualismo que separa a machadas o sujeito do objeto, a mente do corpo ou o espírito da matéria. Sua natureza é transdisciplinar, pois o signo comunicativo é definido como meio por onde a informação passa e se desenvolve, independentemente das ontologias regionais

5 MS: manuscrito seguido pelo número que o identifica, segundo o catálogo Robin. Disponível em: http://www.iupui.edu/ peirce/robin/rcatalog.htm 
que criam as divisões das ciências. Sendo definida a partir da lógica das relações, sua existência não depende do surgimento de tecnologias ou processos historicamente determinados, como é o caso dos meios de comunicação de massa, que fizeram sua entrada na esfera das preocupações sociológicas a partir do século 19, nem das novas mídias interativas, que ganham os holofotes nesta primeira metade do século 21.

Se tivemos, desde a segunda metade do século 20, uma virada informacional nas ciências, a partir da teoria probabilística de Shannon, da descoberta do código genético por Watson e Crick, dos limites à transmissão da informação impostos por Einstein e à incerteza informacional subatômica revelada por Heisenberg, podemos esperar, daqui para frente, uma virada comunicacional em que as questões da semântica não sejam relegadas ao segundo plano, mas ganhem a centralidade que justamente merecem. As questões profundas relativas à vida e à inteligência jamais poderão ser respondidas fora do paradigma semiótico. A contribuição de Peirce à comunicação como metadisciplina ainda aguarda o seu devido reconhecimento.

\section{Referências}

BERGMAN, M. Reflections on the Role of the Communicative Sign in Semeiotic. Transactions of the Charles S. Peirce Society, v.36, n.2, p. 225-254, 2000. Disponível em: <http:// www.helsinki.fi/science/commens/papers/refrole.html>. Acesso em 26 jul. 2016.

FREADMAN, A. The Machinery of Talk. Standford: Standford Univ. Press, 2004. 
HOUSER, N. Introduction. In: HOUSER, N; KLOESEL, C. (Org.). The Essential Peirce (EP), v.1. Bloomington: Indiana Univ. Press, 1992.

HOUSER, N. Introduction. In: The Peirce Edition Project (Org.). The Essential Peirce (EP), v. 2. Bloomington: Indiana Univ. Press, 1998.

IBRI, I. Kósmos Noetós: Arquitetura Metafísica de Charles S. Peirce. São Paulo: Perspectiva, 1992.

MURPHEY, M. G. The development of Peirce's Philosophy. Indianapolis: Hackett, 1993.

PEIRCE, C. S. C. In: HARTSHORNE, C; WEISS, P. (Org. vs 1-6). \& BURKS, A. (Org. vs 7-8). Collected papers of Charles S. Peirce (CP). Cambridge, MA: Harvard University Press, 19311958.

PEIRCE, C. S. In: HOUSER, N; KLOESEL, C. (Org. v.1) \& The Peirce Edition Project (Org. v.2). The Essential Peirce: Selected philosophical writings (EP). Bloomington: Indiana University Press, 1992; 1998.

RANSDELL, J. Charles S. Peirce (1839-1914). In: SEBEOK, T.; ECO, U. (Org.). Encyclopedic Dictionary of Semiotics. The Hague: Mouton de Gruyter, 1986. p. 673-695.

ROMANINI, V. A cifra que se revela: alguns apontamentos biográficos e bibliográficos para tornar mais clara a importância de Peirce para a moderna pesquisa em 
Comunicação. Caligrama, São Paulo, v.1, n.2, 2005. Disponível em: <http://www.revistas.usp.br/caligrama/article/ view/64198>. Acesso em 01 out. 2015.

SANTAELLA, L. 0 método Anticartesiano de C. S. Peirce. São Paulo: Ed. Unesp, 2004.

SAVAN, D. Questions Concerning Certain Classifications Claimed for Signs. Semiotica, v.19, n.3-4, p. 179-195, 1977.

SHANNON, C. The Mathematical Theory of Communication. The Bell System Technical Journal, v. 27, p. 379-423, 1948.

SHORT, T. L. The Development of Peirce's Theory of Signs.

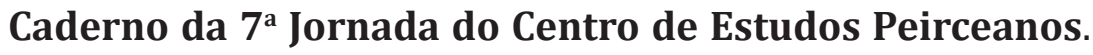
São Paulo: PUCSP, p. 09-22, 2004.

ZEMAN, J. Peirce's Philosophy of Logic. Transactions of C. S. Peirce Society, v. 22, n.1, p. 01-22, 1986.

Artigo recebido em outubro de 2015 e aprovado em abril de 2016.

\section{Como citar este trabalho:}

ROMANINI, Vinicius. A contribuição de Peirce para a teoria da comunicação. CASA: Cadernos de Semiótica Aplicada, São Paulo, v. 14, n. 01, p. 13-56, julho, 2016. Disponível em: <http://seer.fclar.unesp.br/casa>. Acesso em "dia/mês/ano". http://dx.doi.org/10.21709/casa.v14i1.8082. 